\title{
Prosthodontic complications associated with implant retained crowns and bridgework: a review of the literature
}

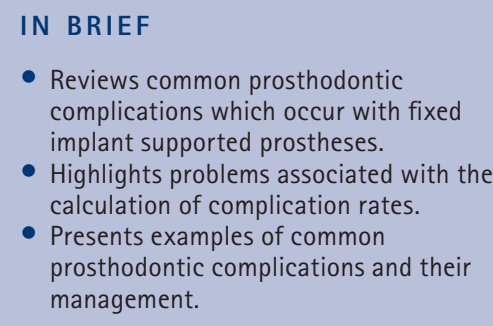

\author{
J. Vere, ${ }^{1}$ S. Bhakta ${ }^{2}$ and R. Patel ${ }^{3}$
}

This article reviews the incidence, aetiology, prevention and management of prosthodontic complications, which may occur following the delivery of implant retained crowns and bridgework. Problems associated with the calculation of complication rates are discussed. Examples of common complications and their management are presented.

\section{INTRODUCTION}

Dental implants have been used to rehabilitate edentulous and partially edentulous patients with fixed prostheses for over 30 years. ${ }^{1}$ Systematic reviews have reported relatively high survival rates for dental implants supporting crowns ${ }^{2}$ and fixed bridgework..$^{3-7}$ However, these reviews have also identified a variety of complications that may be associated with these prostheses. ${ }^{2-7}$ Although these complications rarely result in the complete failure of treatment, their management can be frustrating, expensive and time consuming for the patient, clinician and technician. This review discusses the incidence, aetiology, prevention and management of common prosthodontic complications, which may occur following the delivery of implant retained crowns and bridgework.

\section{COMPLICATIONS}

Prosthodontic complications can be broadly categorised as biological, mechanical and aesthetic. ${ }^{5}$ Biological complications affect the tissues supporting the implant and prosthesis. ${ }^{4}$ Commonly reported biological complications include peri-implant

"Specialist Registrar in Restorative Dentistry, Charles Clifford Dental Hospital, 76 Wellesley Road, Sheffield, South Yorkshire, S10 2SZ: ${ }^{2}$ Consultant in Restorative Dentistry, Leeds Dental Institute, Clarendon Way, Leeds, LS2 8LU; ${ }^{3}$ Consultant in Restorative Dentistry, Charles Clifford Dental Hospital, 76 Wellesley Road, Sheffield, South Yorkshire, S10 2SZ

*Correspondence to: Mr Joe Vere

Email:jwvere@yahoo.co.uk

\section{Refereed Paper}

Accepted 11 January 2012

DOI: 10.1038/sj.bdj.2012.225

${ }^{\circledR}$ British Dental Journal 2012; 212: 267-272 mucositis, peri-implantitis, fistulae at the level of the implant-abutment interface, soft tissue hyperplasia and implant loss. ${ }^{3,4}$ Mechanical complications affect the structural integrity of the implant, abutment or superstructure. ${ }^{6}$ Commonly reported mechanical complications include fracture of the veneering material or framework, loss of retention, screw loosening, screw fracture and implant fracture. ${ }^{2-7}$ Aesthetic complications affect the appearance of the restoration and may be associated with the prosthesis itself or the surrounding soft tissues.

Multiple studies reporting prosthodontic complications associated with implant retained crowns and bridgework have been published..$^{2-7}$ These studies frequently vary in the definition of what constitutes a complication and rarely include all of the complications outlined in this article. Furthermore, these studies are of variable design and quality and use a variety of implant systems and components, many of which are not currently available. ${ }^{2,4,7}$ Unsurprisingly, reported complication rates vary widely. ${ }^{8,9}$ This heterogeneity has prevented the calculation of precise complication rates and as a result, published systematic reviews have reported trends $\mathrm{s}^{3,5}$ or complication rates with wide confidence intervals. ${ }^{2,4,6,7}$ Therefore, published complication rates should be interpreted with caution.

\section{BIOLOGICAL COMPLICATIONS}

Biological complications refer to disturbances in the function of the implant characterised by biological processes that

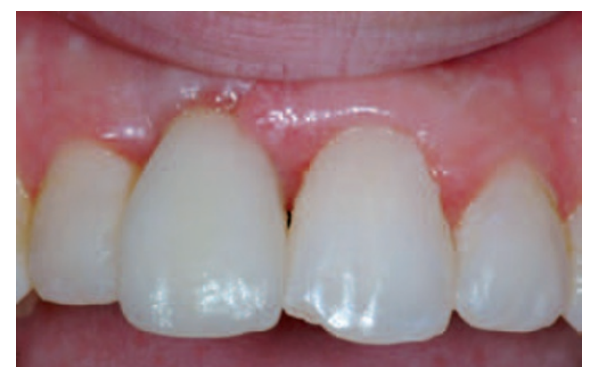

Fig. 1 Peri-implant mucositis associated with implant retained crown UR1

affect the tissues supporting the implant. ${ }^{4}$ Common biological complications include the following.

\section{Peri-implant mucositis}

Peri-implant mucositis is a reversible inflammatory lesion, analogous to gingivitis, affecting the marginal soft tissues surrounding osseointegrated dental implants and is not associated with peri-implant bone loss (Fig. 1). ${ }^{10}$ Peri-implant mucositis may affect up to $50 \%$ of implants and is characterised by bleeding on probing. ${ }^{11}$ Peri-implant mucositis usually resolves with improved homecare, antiseptic mouthwash and careful mechanical cleaning. ${ }^{11,12}$ A lack of keratinised mucosa may impair oral hygiene procedures and increase the incidence of peri-implant mucositis. $^{13}$

\section{Peri-implantitis}

Peri-implantitis is an inflammatory lesion, analogous to periodontal disease, affecting the supporting bone in addition to the soft tissues around an implant. ${ }^{10,14}$ Peri-implantitis is characterised by marginal bone loss and may be associated 
with bleeding on probing, suppuration, pocket formation and mucosal recession. ${ }^{11}$ Marginal bone loss during the first year of function is attributed to remodelling and peri-implantitis cannot be diagnosed until after this time. ${ }^{10}$ It has been suggested that peri-implantitis may be diagnosed when the bone adjacent to $\geq 3$ threads of an implant is lost after one year in function. ${ }^{10}$ However, as implant designs and distances between threads vary, this definition would appear unsatisfactory. Putative risk factors for peri-implantitis include smoking, diabetes mellitus, poor oral hygiene, a history of periodontal disease, interleukin-1 genotype, alcohol, rough surfaced implants, retained cement, (Figs 2 and 3) and poorly fitting abutments or superstructures. ${ }^{3,14,15}$ A lack of keratinised mucosa does not appear to be associated with an increased incidence of peri-implantitis. ${ }^{13}$ Jung et al. ${ }^{2}$ reported that $6.3 \%$ of implant supported single crowns had bone loss $>2 \mathrm{~mm}$ over a 5 year observation period. Pjetursson et al. ${ }^{7}$ reported that less than $8.6 \%$ (95\% CI; 5.1\%-14.1\%) of implant supported fixed partial dentures were affected by peri-implantitis over 5 years. However, much higher incidences have been reported in other studies. ${ }^{11}$

Following the provision of an implant retained crown or bridge baseline periimplant pocket depths and radiographic bone levels should be established. ${ }^{11}$ Gentle probing $(\leq 0.25 \mathrm{~N})$ is unlikely to damage the implant surface or the epithelial attachment and should be repeated annually. ${ }^{10,11,14}$ Studies suggest that future attachment loss is unlikely to occur in the absence of bleeding on probing. ${ }^{14}$ Probing depths are generally greater around implants than teeth and a probing depth of $6 \mathrm{~mm}$ is not uncommon in health. ${ }^{16}$ Periapical radiographs should not be routinely prescribed during follow-up and should only be taken when changes in clinical parameters indicate disease. ${ }^{17}$ Radiographs should be interpreted cautiously because they only show interproximal bone levels and have poor reproducibility. ${ }^{14,18}$

There is little evidence to favour either the non-surgical or surgical management of peri-implantitis. ${ }^{19}$ However, a surgical approach is often preferred as it offers improved access. ${ }^{14}$ Implant surfaces may be cleaned mechanically, chemically, by laser or air abrasion. ${ }^{20}$ No single method of

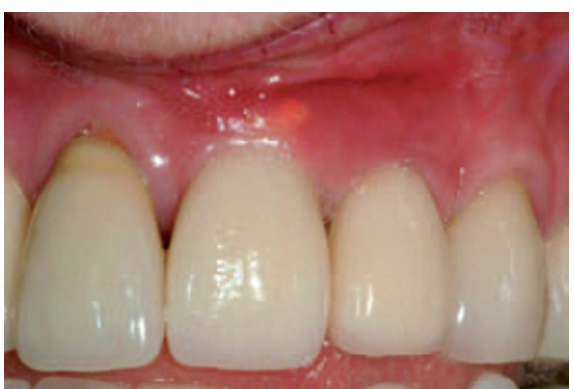

Fig. 2 Retained cement associated with implant crowns UL1 and UL2

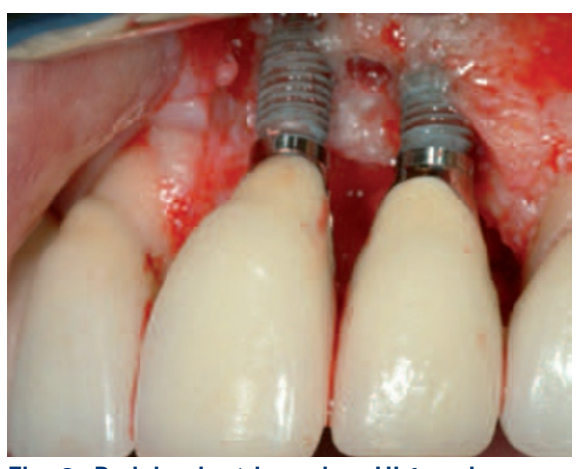

Fig. 3 Peri-implant bone loss UL1 and UL2 visible following mucoperiosteal flap elevation

surface debridement has been shown to be superior. ${ }^{11,19,20}$ Where mechanical debridement is undertaken, plastic or titanium curettes have been recommended to avoid damaging the implant surface. ${ }^{10}$ However, Romeo et al. ${ }^{21}$ have reported promising results following the deliberate removal of the implant surface. Guided bone regeneration may be used in conjunction with surgical debridement and this may result in greater bony infill although re-osseointegration is unlikely to occur. ${ }^{20}$ Studies suggest that surgical debridement may be successful in $60-100 \%$ of cases. ${ }^{20,21}$

\section{Fistulae}

Fistulae have been reported at the level of the implant-abutment interface in 1\% of cases (study duration not reported) 5 (Fig. 4) and they are usually associated with loose abutments screws or ill-fitting frameworks. ${ }^{3}$ These fistulae usually resolve following removal of the prosthesis, irrigation with $0.2 \%$ chlorhexidine gluconate (Corsodyl, GlaxoSmithKline) and replacement of the prosthesis at the correct torque. When a prosthesis is found to be ill-fitting it should be remade. When fistulae occur in conjunction with temporary metal cylinders, corrosion products may cause permanent discolouration of the soft tissues (Fig. 5).

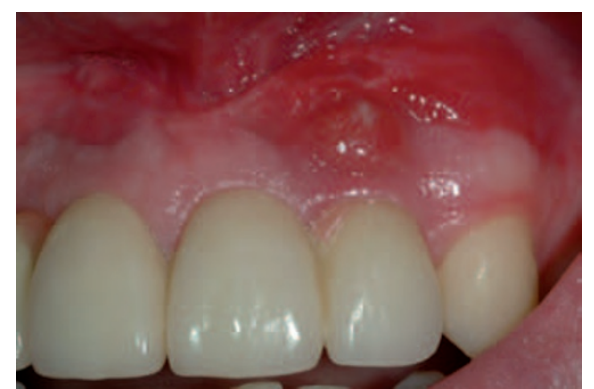

Fig. 4 Fistula associated with a loose abutment screw UL2

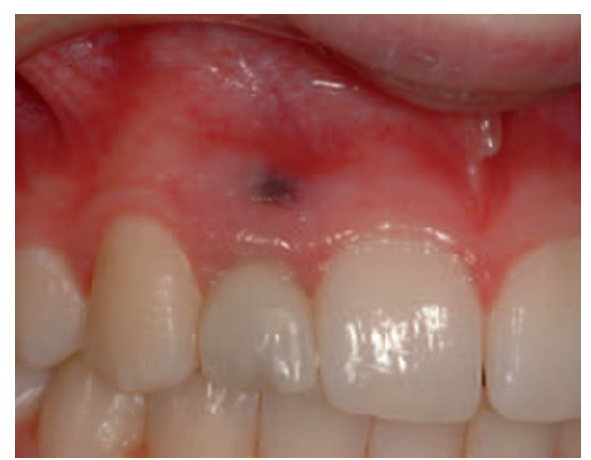

Fig. 5 Healed fistula with permanent mucosal discolouration associated with temporary implant retained crown at UR2 site

\section{Soft tissue hyperplasia}

Hyperplasia of the peri-implant tissues has been reported to affect up to 20\% of fixed prostheses over a 9 year observation period. ${ }^{3}$ This hyperplasia represents an over-exaggerated response to plaque accumulation and may be associated with poor oral hygiene, framework misfit, dead space beneath frameworks and a lack of attached gingivae. ${ }^{3}$ Hyperplasia usually resolves following correction of predisposing factors, improved oral hygiene and mechanical debridement. However, it may occasionally be necessary to surgically resect the hyperplastic tissue (Figs 6-9). Figures 6-9 show a case which required surgical resection following lack of resolution after initial debridement and improvement of oral hygiene. The use of electrosurgery is discouraged in these situations as there may be accidental heating of the implant-bone interface.

\section{Implant loss}

Implant losses are categorised as early or late. ${ }^{3}$ Early implant loss occurs before functional loading and results from a failure to establish osseointegration. ${ }^{18}$ Early implant loss has been associated with overheating during implant placement, infection, poor bone quantity and poor bone quality. ${ }^{18}$ 
Late implant loss occurs following functional loading because of a breakdown of an established osseointegration. ${ }^{18}$ Late implant loss has been associated with occlusal overload, peri-implantitis, poor bone quantity and poor bone quality. ${ }^{18,22}$ The reported survival rates for implants supporting crowns and fixed partial dentures exceed 95\% over 5 years ${ }^{2,6,7}$ and 93\% over 10 years. ${ }^{6,7}$ However, survival does not equate to success and these rates must be interpreted cautiously because a surviving implant may be failing, unrestorable or may have had extensive remedial treatment. ${ }^{16}$ When implant loss occurs, it occurs before functional loading in approximately $55 \%$ of cases. ${ }^{4,22}$ When an implant fails an alternative treatment may be considered, the site may be allowed to heal before placing a new implant (Figs 10 and 11) or a new, wider implant may be placed immediately. ${ }^{23}$ There is limited evidence to suggest that implants placed at the site of previously failed implants have lower survival rates. ${ }^{23}$ However, this may simply reflect poor initial case selection.

\section{MECHANICAL COMPLICATIONS}

Commonly reported mechanical complications associated with implant supported fixed prostheses include fracture of the veneering material or framework, loss of retention, screw loosening, screw fracture and implant fracture. ${ }^{2,6,7}$ The incidence of these complications associated with implant retained single crowns, ${ }^{2}$ and implant retained fixed partial dentures ${ }^{7}$ with or without cantilever extensions, ${ }^{6}$ after five years, is presented in Table 1 .

Mechanical complications occur when the capacity of the prosthesis to withstand applied forces is exceeded. The precise complication will depend upon the magnitude and the direction of the applied force. However, the weakest parts of the system, that is, the screws and veneering material, are usually affected (Table 1). Implant supported prostheses are believed to be particularly susceptible to mechanical complications because implants have limited proprioception and adaptive capacity. ${ }^{24}$ Excessive loading has been associated with non axial forces, cantilevers, parafunction and increased implantabutment ratios. ${ }^{25,26,27}$ Mechanical complications have also been associated with the inappropriate selection or use of materials,

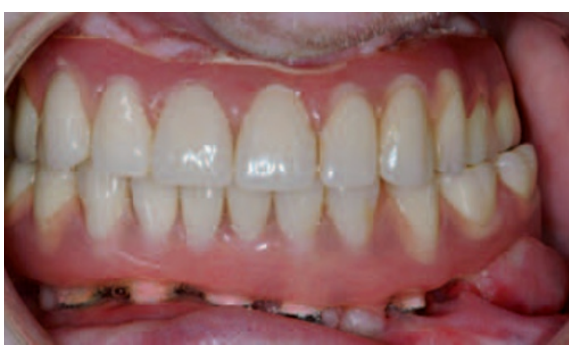

Fig. 6 Hyperplasia of the peri-implant soft tissues associated with the distal aspect of an ill-fitting lower implant retained bridge

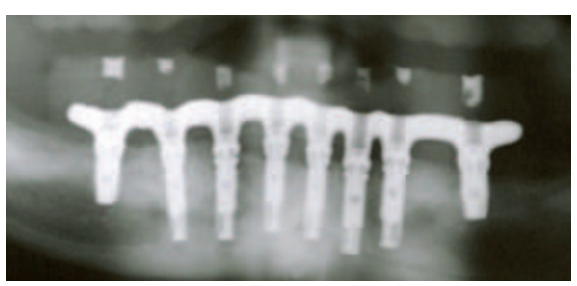

Fig. 7 Radiograph of case shown in Fig. 6. Superstructure is ill fitting at LR3, LL3 and LL4 sites

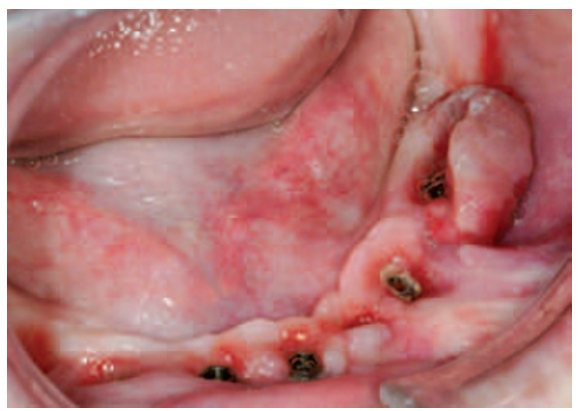

Fig. 8 The full extent of soft tissue hyperplasia is revealed following removal of the superstructure shown in Fig. 6

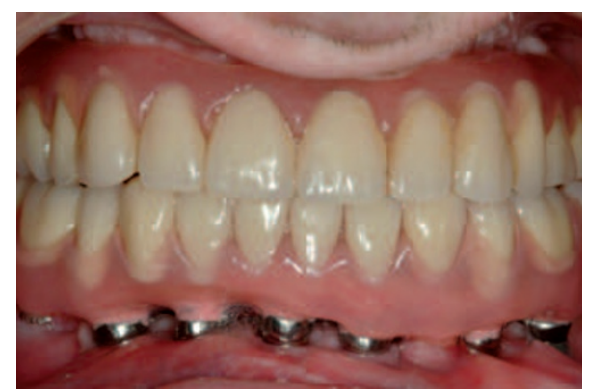

Fig. 9 Resolution of the soft tissue hyperplasia shown in Fig. 8

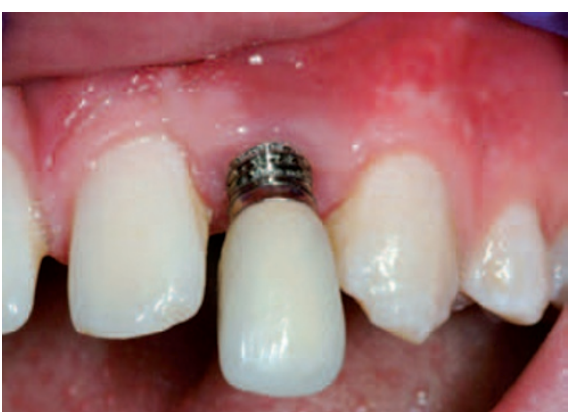

Fig. 10 Failing implant UL2

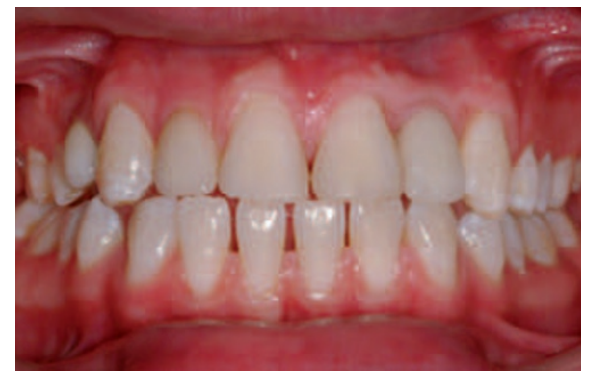

Fig. 11 New implant placed following a 6 month period of bony healing. Midline diastema has been closed with direct composite

\begin{tabular}{|c|c|c|c|}
\hline Complication & Implant single crowns ${ }^{2}$ & $\begin{array}{l}\text { Implant retained fixed } \\
\text { partial dentures }^{7}\end{array}$ & $\begin{array}{l}\text { Implant retained fixed partial } \\
\text { dentures with cantilevers }{ }^{6}\end{array}$ \\
\hline Screw loosening & $12.7 \%(5.7 \%-27 \%)$ & $5.8 \%(3.8 \%-8.7 \%)$ & $8.2 \%(3.9 \%-17 \%)$ \\
\hline Loss of retention & $5.5 \%(2.2 \%-13.5 \%)$ & Not reported & $5.7 \%(1.0 \%-16.5 \%)$ \\
\hline Veneer fracture & $4.5 \%(2.4 \%-8.4 \%)$ & $13.2 \%(8.3 \%-20.6 \%)$ & $10.3 \%(3.9 \%-26.6 \%)$ \\
\hline Framework fracture & $3 \%(1.1 \%-8.3 \%)$ & $0.8 \%(0.4 \%-1.8 \%)$ & 0 \\
\hline Screw fracture & $0.35 \%(0.09 \%-1.4 \%)$ & $1.5 \%(0.8 \%-2.8 \%)$ & $2.1 \%(0.9 \%-5.1 \%)$ \\
\hline Implant fracture & $0.14 \%(0 \%-0.64 \%)$ & $0.4 \%(0.1 \%-1.2 \%)$ & $1.3 \%(0.2 \%-8.3 \%)$ \\
\hline
\end{tabular}

manufacturing imperfections, ill-fitting frameworks and trauma. ${ }^{3,28,29}$

In partially edentulous patients implant supported prostheses should be designed so that they allow light occlusal contact in the intercuspal position. This allows for compression of the periodontal ligament of adjacent teeth during function and reduces excessive occlusal loading on the implants. ${ }^{24}$ Furthermore, wherever possible, occlusal forces should be directed axially, occlusal tables should be narrow with shallow cuspal inclines, cantilevers should be minimised and eccentric excursions should be guided by natural teeth..$^{24,27}$ Following treatment, hard nocturnal 
splints have been advocated to reduce the incidence of mechanical complications. ${ }^{25}$ However, these are only likely to be effective if patient compliance is good. Frameworks should be constructed from appropriate materials, be of adequate thickness and designed appropriately to support the veneering material which may be porcelain, acrylic or composite resin..$^{3,28}$ Frameworks milled using CAD-CAM (computer aided design-computer aided manufacture) technology are preferable as they are not susceptible to distortion or casting porosity and have improved marginal fit when compared to cast gold frameworks. ${ }^{30}$ However, the accuracy of a CAD-CAM framework is still dependent upon the accuracy of the cast model, the scanning technique and the computer based designing capabilities of the dental technician.

\section{Fracture of the veneering material or framework}

Fracture of the veneering material is one of the most common mechanical complications reported in the literature (Figs 12 and 13). Early studies reported incidences as high as 30\% over 3 years, ${ }^{3}$ although this incidence has reduced (Table 1). Superstructures may be veneered with porcelain, acrylic or composite resin. Porcelain maintains appearance, is least likely to fracture and is often considered the veneering material of choice. ${ }^{3,5,7}$ Fracture of the underlying framework is less common (Table 1, Fig. 14). ${ }^{5}$

When a superstructure fractures it is important to address the cause of fracture before any remedial treatment (Fig. 14). Small fractures in non aesthetic areas can be smoothed while larger fractures usually require repair. Minor fractures can be repaired intra-orally using metal-ceramic repair systems, such as Cojet $\left(3 \mathrm{M}^{\mathrm{TM}} \mathrm{ESPE}^{\mathrm{TM}}\right)$. However, the clinical performance of these repairs is uncertain. ${ }^{43}$ It is usually preferable to remove fractured superstructures and repair them in the laboratory. This process is facilitated when restorations are screw-retained. ${ }^{15}$ If provisional restorations have been retained, they can be replaced to maintain aesthetics and function while repairs are undertaken. Porcelain absorbs water intra-orally and may crack when re-introduced into a ceramming furnace. Therefore, superstructures veneered with porcelain must be thoroughly dried

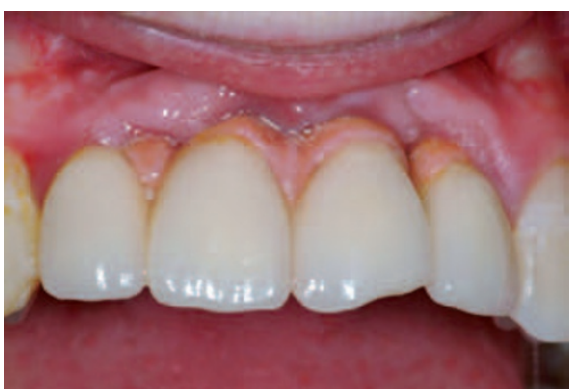

Fig. 12 Fractured porcelain UL1

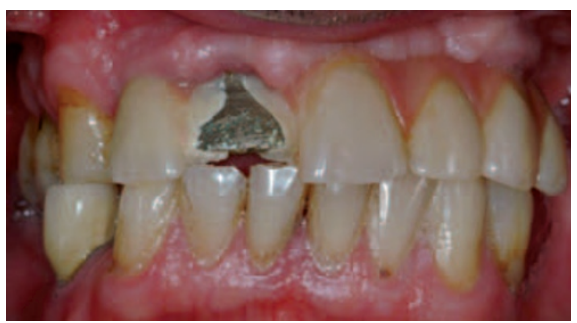

Fig. 13 Screw retained implant bridge with fractured composite veneer UR1

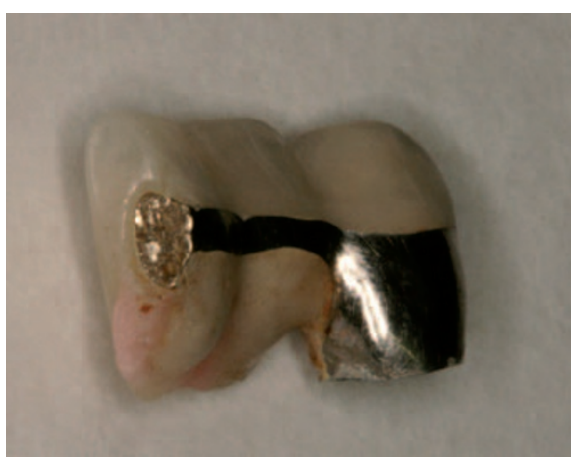

Fig. 14 Midline fracture of implant retained bridge replacing LR3-LL3. Metalwork is too thin in cross-section

in a low temperature desiccator before attempting repair. ${ }^{32}$ Complex restorations with individual crowns cemented on to implant retained superstructures have been described in the literature. ${ }^{33}$ These restorations are designed so that individual crowns can easily be replaced in the event of fracture, however, they are expensive and complex to manufacture. When recurrent veneer fracture occurs occlusal and palatal surfaces may be constructed in metal.

\section{Loss of retention}

Loss of retention is a complication specific to cement retained prosthesis. Loss of retention is commonly associated with abutments that provide inadequate retention or resistance form (Fig. 15). This usually reflects incorrect abutment selection, poor abutment design or a lack of restorative space. The amount of restorative space

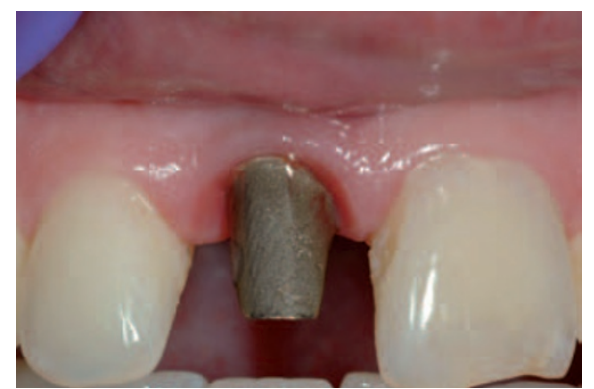

Fig. 15 Decemented crown. Custom abutment has excessive axial taper

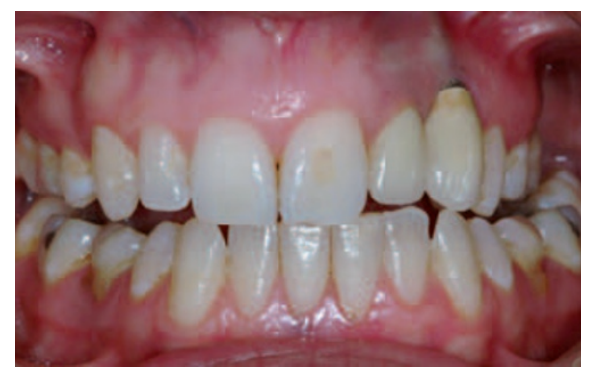

Fig. 16 Loose abutment screw UL3 implant retained crown. UL3 provides sole guidance in left lateral excursion

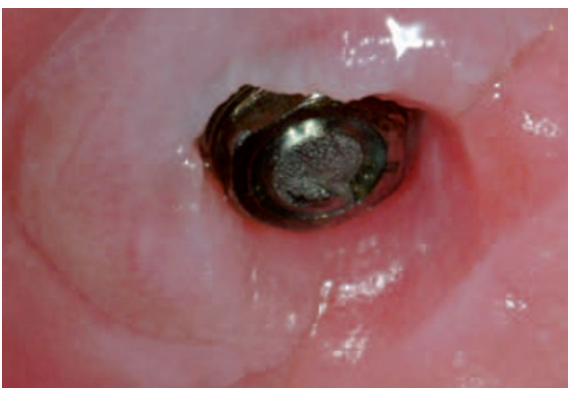

Fig. 17 Fractured abutment screw

should be assessed before implant placement. When restorative space is limited, provided bone volume is adequate, consideration should be given to deeper placement of the implant.

\section{Screw loosening and screw fracture}

Screw loosening is a commonly encountered complication, as indicated in Table 1. Most studies do not differentiate between prosthesis and abutment screws, therefore they are considered together in this article. The shanks of abutment and prosthetic screws are designed to stretch upon insertion. The tension generated by stretching is termed preload and maintains the integrity of the joint. ${ }^{34}$ Screw loosening usually occurs as a result of micromovement at the joint interface. This micromovement may be associated with an inadequate initial torque, illfitting frameworks and occlusal overload 


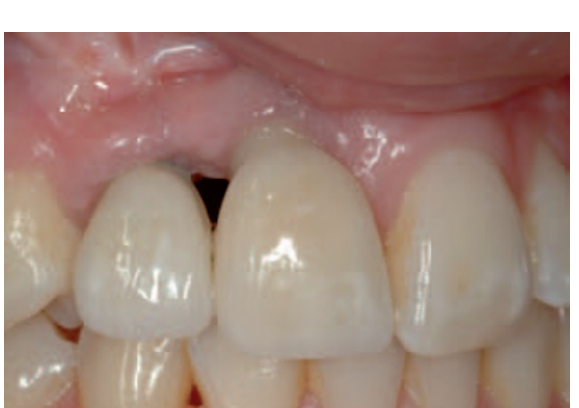

Fig. 18 Absent interdental papilla between implants at UR1 and UR2 sites

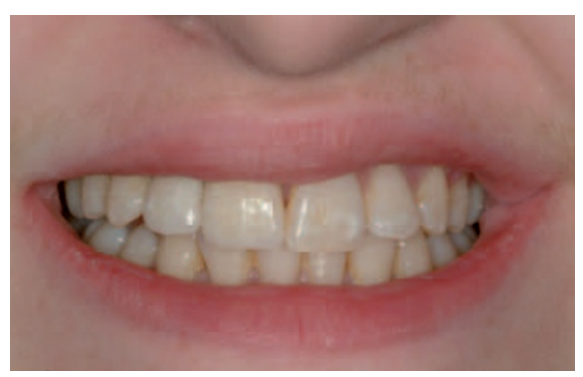

Fig. 19 Smile line of patient in Fig. 18

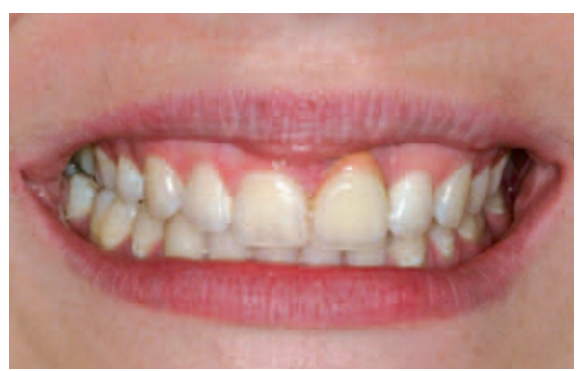

Fig. 20 Implant retained crown UL1: a disastrous result in a young girl with a high lip line

(Fig. 16). ${ }^{3}$ Early studies reported very high incidences of screw loosening, ${ }^{3}$ however, alterations in screw design, materials and surface coatings in conjunction with a move towards implants with internal connections appear to have considerably reduced the incidence. ${ }^{28}$ Screws should be inserted at the correct torque and reused with care because their mechanical properties may have altered. ${ }^{34}$ Fractured screws are relatively unusual (Fig. 17) and may be associated with over-torquing, occlusal overload and ill-fitting frameworks. $^{3}$ Fractured screws can often be unwound with a probe or an ultrasonic scaler. However, it is occasionally necessary to use a proprietary screw removal kit or cut a slot in the coronal aspect of the fractured screw to allow the engagement of a screwdriver. Care should be taken to avoid damaging the internal threads of the implant when the slot is prepared and magnification is advised.

\section{Implant fracture}

Implant fracture is a rare occurrence, which usually affects hollow or narrow diameter implants. ${ }^{4,29}$ Implant fracture is usually catastrophic and necessitates removal or submergence of the fractured fragment. Occasionally the fractured implant may be recontoured and salvaged. ${ }^{29}$

\section{AESTHETIC COMPLICATIONS}

Aesthetic complications detract from the overall appearance of the implant supported prosthesis. Missing interdental papillae (Fig. 18), mucosal recession, poor restoration contour and shade mismatch may all cause aesthetic failure. ${ }^{35}$ Implant supported restorations have been considered successful when they mimic adjacent natural teeth in a well balanced soft tissue framework. ${ }^{36}$ However, aesthetic outcomes are highly subjective and care should be taken to avoid imposing our own aesthetic parameters on patients. Studies have revealed that there is often poor agreement between patients and professionals regarding aesthetic outcome ${ }^{37}$ and that patients are usually highly satisfied with the aesthetic outcome. ${ }^{38,39}$ Several reviews have reported an overall aesthetic complication rate approaching 10\%., ${ }^{2,5}$ However, neither of these reviews reported the criteria used to assess appearance.

The final aesthetic outcome is largely dependent upon the pre-existing state of the hard and soft tissues, ${ }^{35,40,41}$ the care with which surgical procedures are performed $^{42,43}$ and lip position (Fig. 19). Operator experience and patient selection are important factors and it is vital that the implants are placed in the correct three dimensional position. Careful preoperative assessment can usually inform us as to the likely cosmetic result. The patient's existing prosthesis, photographs and rehearsals can be used to communicate this to the patient. Where deficiencies are identified with the hard and soft tissues preoperatively, augmentation procedures may be considered, or the patient may elect to accept a compromised result. ${ }^{42,43}$

Patients complaining of poor aesthetics following the completion of treatment can be challenging to manage. Mucogingival grafting $^{44}$ and the use of pink porcelain may be useful in these cases. However, inadequate treatment planning and poor implant positioning can often not be disguised (Fig. 20).

\section{CONCLUSIONS}

Although implant retained crowns and bridgework are highly successful they may be associated with a variety of biological, mechanical and aesthetic complications. The precise incidence of these complications is unclear and future studies should report complications according to standardised criteria. Clinicians providing implant treatment should be aware of these potential complications and the strategies by which they can be prevented and managed. Potential complications should be communicated to the patient before commencing treatment as part of the informed consent process. Clinicians are encouraged to audit their own work and determine their personal complication rates.

1. Jemt T, Lekholm U, Adell R. Osseointegrated implants in the treatment of partially edentulous patients: a preliminary study on 876 consecutively placed fixtures. Int J Oral Maxillofac Implants 1989; 4: 211-217.

2. Jung R E, Pjetursson B E, Glauser $R$, Zembic $A$, Zwahlen M, Lang N P. A systematic review of the 5 -year survival and complication rates of implant supported single crowns. Clin Oral Implants Res 2008; 19: 119-130.

3. Goodacre C J, Kan J Y, Rungcharassaeng K. Clinical complications of osseointegrated implants. J Prosthet Dent 1999; 81: 537-552.

4. Berglundh $T$, Persson $L$, Klinge B. A systematic review of the incidence of biological and technical complications in implant dentistry reported in prospective longitudinal studies of at least 5 years. J Clin Periodontol 2002; 29: 197-212.

5. Goodacre C J, Bernal G, Rungcharassaeng K, Kan J Y. Clinical complications with implants and implant prostheses. J Prosthet Dent 2003; 90: 121-132.

6. Aglietta M, Siciliano V I, Zwahlen M et al. A systematic review of the survival and complication rates of implant supported fixed dental prostheses with cantilever extensions after an observation period of at least 5 years. Clin Oral Implants Res 2009; 20: 441-451.

7. Pjetursson $B E_{1}$ Tan $K_{1}$ Lang N P, Brägger $U$, Egger $M$ Zwahlen M. A systematic review of the survival and complication rates of fixed partial dentures (FPDs) after an observation period of at least 5 years. Clin Oral Implants Res 2004; 15: 625-642.

8. Nedir R, Bischof M, Szmukler-Moncler S, Belser U C, Samson J. Prosthetic complications with dental implants: from an up-to-8-year experience in private practice. Int J Oral Maxillofac Implants 2006; 21: 919-928.

9. Ortorp A, Jemt T. Clinical experiences of implantsupported prostheses with laser-welded titanium frameworks in the partially edentulous jaw: a 5 -year follow-up study. Clin Implant Dent Relat Res 1999; 1: 84-91.

10. Heasman P, Esmail Z, Barclay C. Peri-implant diseases. Dental Update 2010; 37: 511-512, 514-516.

11. Lindhe J, Meyle J. Peri-implant diseases: consensus report of the sixth European workshop on periodontology. J Clin Periodontol 2008; 35: 282-285.

12. Renvert $\mathrm{S}$, Roos-Jansåker $A$ M, Claffey N. Nonsurgical treatment of peri-implantitis and periimplantitis: a literature review. J Clin Periodontol 2008; 35: 305-315.

13. Chung D M, Oh T J, Shotwell J L, Misch C E, Wang $H$ L. Significance of keratinized mucosa in maintenance of dental implants with different surfaces. J Periodontol 2006; 77: 1410-1420.

14. Heitz-Mayfield L J. Peri-implant diseases: diagnosis and risk indicators. J Clin Periodontol 2008; 35: 292-304. 
15. Chee W, Jivraj S. Screw versus cemented implant supported restorations. Br Dent J 2006: 201: 501-507.

16. Misch C, Perel M, Wang H L et al. Implant success, survival and failure: the International Congress of Oral Implantologists (ICOI) Pisa consensus conference. Implant Dentistry 2008; 17: 5-15.

17. Lang N P, Berglundh T. Peri-implant disease: where are we now? Consensus of the seventh European workshop on periodontology. J Clin Periodontol 2011; 38: 178-181.

18. Esposito M, Hirsch J M, Lekholm U, Thomsen P. Biological factors contributing to failures of osseointegrated implants (I). Success criteria and epidemiology. Eur J Oral Sci 1998; 106: 527-551.

19. Esposito M, Grusovin G, Tzanetea E, Piattelli A, Worthington $\mathrm{H} \mathrm{V}$. Interventions for replacing missing teeth: treatment of peri-implantitis. Cochrane Database Syst Rev 2010, 6: CD004970.

20. Claffey N, Clarke E, Polyzois I, Renvert S. Surgical treatment of peri-implantitis. J Clin Periodontol 2008; 35: 316-332.

21. Romeo E, Lops D, Chiapasco M, Ghisolfi M, Vogel G. Therapy of peri-implantitis with resective surgery. A 3-year clinical trial on rough screw-shaped oral implants. Part II: radiographic dutcome. Clin Oral Implants Res 2007: 18: 179-187.

22. Alsaadi G, Quirynen $M$, Komárek $A$, van Steenberghe D. Impact of local and systemic factors on the incidence of oral implant failures, up to abutment connection. J Clin Periodontol 2007: 34: 610-617.

23. Grossmann $Y$, Levin L. Success and survival of single dental implants placed in sites of previously failed implants. J Periodonto/ 2007: 78: 1670-1674.

24. Davies S J. Occlusal considerations in implantology: good occlusal practice in implantology. Dental Update 2010; 37: 610-612, 615-616, 619-620.

25. Lobbezoo F, Brouwers J E, Cune M S, Naeije M.
Dental implants in patients with bruxing habits. J Oral Rehabil 2006; 33: 152-159.

26. Blanes $\mathrm{R} J$. To what extent does the crown-implant ratio affect the survival and complications of implant-supported reconstructions? A systematic review. Clin Oral Implants Res 2009; 20: 67-72.

27. Zurdo J, Romão C, Wennström J L. Survival and complication rates of implant-supported fixed partial dentures with cantilevers: a systematic review. Clin Oral Implants Res 2009; 20: 59-66.

28. Kreissl M E, Gerds T, Muche R, Heydecke G, Strub J R. Technical complications of implant-supported fixed partial dentures in partially edentulous cases after an average observation period of 5 years. Clin Oral Implants Res 2007; 18: 720-726.

29. Virdee P, Bishop K. A review of the aetiology and management of fractured dental implants and a case report. Br Dent J 2007; 203: 461-466.

30. Torsello F, di Torresanto V M, Ercoli C, Cordaro L. Evaluation of the marginal precision of one-piece complete arch titanium frameworks fabricated using five different methods for implant-supported restorations. Clin Oral Implants Res 2008; 19: 772-779.

31. dos Santos J G. Fonseca R G, Adabo G L, dos Santos Cruz C A. Shear bond strength of metal-ceramic repair systems. J Prosthet Dent 2006; 96: 165-173.

32. McCabe J F, Walls A. Applied dental materials. $9^{\text {th }}$ ed. Oxford: John Wiley and Sons, 2008.

33. Tipton P A. Esthetic restoration of the traumatized and surgically reconstructed anterior maxilla. J Esthet Restor Dent 2002; 14: 267-274.

34. Byrne D, Jacobs S, O'Connell B, Houston F, Claffey $N$. Preloads generated with repeated tightening in three types of screws used in dental implant assemblies. J Prosthodont 2006; 15: 164-171.

35. Buser D, Martin W, Belser U. Optimising esthetics for implant restorations in the anterior maxilla: anatomic and surgical considerations. Int J Oral
Maxillofac Implants 2004; 19 Suppl: 43-61.

36. Al-Harbi S A, Edgin W A. Preservation of soft tissue contours with immediate screw-retained provisional implant crown. J Prosthet Dent 2007; 98: 329-332.

37. Esposito M, Grusovin M G, Worthingtom H V. Agreement of quantitative subjective evaluation of esthetic changes in implant dentistry by patients and practitioners. Int J Oral Maxillofac Implants 2009; 24: 309-315.

38. Levi A, Psoter W J, Agar J R, Reisine S T, Taylor T D. Patient self-reported satisfaction with maxillary anterior dental implant treatment. Int J Oral Maxillofac Implants 2003; 18: 113-120.

39. Vermylen $K$, Collaert $B$, Lindén U, Björn A-L, De Bruyn $H$. Patient satisfaction and quality of single tooth restorations. Clin Oral Implants Res 2003; 14: 119-124.

40. Choquet $V$, Hermans $M$, Adriaenssens $P$, Daelemans P, Tarnow D P, Malevez C. Clinical and radiographic evaluation of the papilla level adjacent to singletooth dental implants. A retrospective study in the maxillary anterior region. J Periodontol 2001; 72: 1364-1371.

41. Tarnow D P, Cho S C, Wallace S S. The effect of inter-implant distance on the height of inter-implant bone crest. J Periodonto/ 2000; 71: 546-549.

42. Palacci P, Ericsson I. Esthetic implant dentistry soft and hard tissue management. Chicago: Quintessence Publishing Co Inc., 2001.

43. Sclar A G. Soft tissue and esthetic considerations in implant therapy. US: Quintessence Publishing Co Inc., 2003.

44. Burkhardt $R$, Joss A, Lang N P. Soft tissue dehiscence coverage around endosseous implants: a prospective cohort study. Clin Oral Implants Res 2008; 19: 451-457.

\section{Erratum}

Research article (BDJ 2012; 212: E5)

'Complexities associated with orthodontic services in the National Health Service'

In the above research article on page 7 , the number ' 2.5 ' should have been '22.5' in the following sentence:

'One of the KPIs is that orthodontic contracts should, as a minimum, deliver a number of treatments equal to contracted UOAs divided by 2.5.' 